\title{
Human Factors and Neurophysiological Metrics in Air Traffic Control: a Critical Review
}

\author{
Pietro Aricò, Gianluca Borghini, Gianluca Di Flumeri, Student Member, IEEE, Stefano Bonelli, \\ Alessia Golfetti, Ilenia Graziani, Simone Pozzi, Jean-Paul. Imbert, Géraud Granger, Railane \\ Benhacene, Dirk Schaefer, Fabio Babiloni, Member, IEEE *
}

\begin{abstract}
This article provides the reader a focused and organised review of the research progresses on neurophysiological indicators, also called "neurometrics", to show how neurometrics could effectively address some of the most important Human Factors (HFs) needs in the Air Traffic Management (ATM) field. The state of the art on the most involved HFs and related cognitive processes (e.g. mental workload, cognitive training) is presented together with examples of possible applications in the current and future ATM scenarios, in order to better understand and highlight the available opportunities of such neuroscientific applications. Furthermore, the paper will discuss the potential enhancement that further research and development activities could bring to the efficiency and safety of the ATM service.
\end{abstract}

\section{INTRODUCTION}

Nowadays, Air Traffic Control Officers (ATCOs) tend to work in very complex systems, in which a proficient interaction between humans and computer systems is crucial to provide a safe and efficient service. Dealing with an exponentially increasing of automation systems, the urgent need is to have reliable and precise tools to support the design phase of new technology and solutions, to increase the availability of advanced automations (e.g. adaptive automation, [1]), and to enhance the operators' training assessment and effectiveness. Technologies and techniques based on the analysis of neurophysiological signals (e.g. the

*Pietro Aricò, Gianluca Borghini and Gianluca Di Flumeri contributed equally to this work.

P. Aricò§, G. Borghini and F. Babiloni are with Dept. Molecular Medicine, Sapienza University of Rome, Italy, BrainSigns srl, Rome, Italy and Fondazione Santa Lucia, Rome, Italy (\$corresponding author: phone: +39 06 51501163; e-mail: pietro.arico - gianluca.borghini fabio.babiloni@uniroma1.it).

G. Di Flumeri is with Dept. Anatomical, Histological, Forensic \& Orthopedic Sciences, Sapienza University of Rome, Italy, BrainSigns srl, Rome, Italy and Fondazione Santa Lucia, Rome, Italy (gianluca.diflumeri@uniroma1.it).

S. Bonelli, A. Golfetti, I. Graziani and S. Pozzi are with DeepBlue srl,, Rome, Italy (stefano.bonelli - alessia.golfetti - ilenia.graziani simone.pozzi@dblue.it).

J.P. Imbert, G. Granger, R. Benhacene are with École Nationale de l'Aviation Civile (ENAC), Toulouse, France (jean-paul.imbert geraud.granger - railane.benhacene@enac.fr).

D. Schaefer is with Eurocontrol Experimental Centre, Les Bordes, France (dirk.schaefer@eurocontrol.int).
Electroencephalogram, EEG) have the potential of providing reliable information about operators' internal state [2]-[5], understanding, for example, if the operator's workload is exceeding his/her cognitive capacity, or if some kind of incapacitation is occurring.

The paper is structured in three main sections. In the first one, the Air Traffic Control (ATC) domain is briefly introduced, highlighting the importance of Human Factor (HF) concepts in operational environments. Then, the main benefits from the introduction of neurophysiological measurements of the operator's cognitive state are presented. In the second section, the topic is the selection of the most relevant HF concepts in the ATC field, and the discussion of the corresponding research studies. In particular, the mental workload assessment during ATC activities, HumanMachine Interaction (HMI) in adaptive automation applications, and operators' training and expertise assessment are presented.

In the third section, examples of future application of neurometrics in the ATM domain are provided.

\section{HUMAN FACTORS IN ATM}

\section{A. Air Traffic Management (ATM)}

Air Traffic Management (ATM) is a term largely used to encompass all systems that assist aircraft from departing, transit airspace, to landing. It includes different sectors, such as Air Traffic Control (ATC), Air Traffic Flow Management (ATFM), and Aeronautical Information Services (AIS). Rather than discussing all these aspects of the ATM systems, the remainder of this review will focus on the ATC area. In this domain, the operator, i.e. the ATCO, has to monitor the aircraft assumed in the air - sector of his/her responsibility, and provide assistance to the pilots for safe, efficient and smooth navigation, intervening in case of risk of infringing the prescribed safety separations between aircraft. In their review, "The levels of automation", Parasuraman, Sheridan and Wickens [6] argue that safety critical systems, such as the ATC systems, are typically less automated than one could expect. Compared to other safety critical and high-hazard domains, ATC is characterized by the key role played by human actors. As a matter of fact, safety relevant 
decisions are made mostly by humans, whereas computer systems are used as supporting tools, assisting the controller in monitoring and communication tasks. Automation systems mainly support information acquisition and information analysis activities.

\section{B. Human Factors measurement needs in ATC}

In the ATC system the controller's work is very cognitively demanding. Activities for managing air traffic, such as solving conflicts, maintaining separation between aircraft and coordinating air-traffic, involve cognitive processes such as visual scanning, information processing, decision making and attention. Controllers have a key-role in facing system complexity, because their main objective is to anticipate and manage unpredictable situations affected by multiple elements. Complexity does not regard only the environment. Radio communications, phone communications, radar displays and computers are also system elements that increase the ATC system complexity. A peculiar characteristic of the ATC work is that controllers usually perform few recurring tasks in addition to the routine activity, such as welcoming aircraft on the frequency and handing them off to adjacent sectors. Even if these tasks are well known, their order remains largely unpredictable because of the dynamic nature of weather, traffic demands, operational conditions, and so on.

HFs have been always a major research topic in the Aviation field [7] and most of the advanced technologies are studied and applied in this domain [8]. In other words, Aviation recognised the importance of "the design and evaluation of operational and humans limits" since a long time ago ${ }^{1}$. With the contribution of other disciplines, such as cognitive psychology, neuroergonomics, engineering and industrial design, several methods have been developed over time in order to better understand the interaction between humans and complex systems [9]. These methods have been recognised to be crucial elements in the design, management and analysis of the ATM system. The knowledge about human factors has evolved along the years to cope with technological and social changes.

It is expected that these changes will stress the need for more accurate and reliable methodologies to investigate, understand and assess the human role in the challenging future ATM scenarios.

\section{The ATC expected needs in the upcoming future}

At present, the ATC systems in Europe (and in other parts of the world, most notably the United States) are not drastically different from their historic predecessors in the 1950's (when the primary radar was introduced) and 1960's (when secondary radar came about) ${ }^{2}$.

${ }^{1} \mathrm{http} / / \mathrm{www}$.iso.org/iso/catalogue detail?csnumber=35885

2 http://www.eurocontrol.int/sites/default/files/publication/files/prr-2013.pdf
Furthermore, due to changes in traffic volume, traffic complexity and economy, the main concerns of ATM (e.g., flights delay, cost-efficiency) changed with respect to a decade ago. The Single European Sky (SES) initiative aims at enhancing the current air traffic safety, to contribute to the sustainable development of the air transport system and to improve the overall performance of ATM. Its primary objective is to meet future capacity, safety and cost-efficiency needs through legislation and technology changes. A key point to reach the full implementation of SES initiative is the development of new ATM technologies and procedures. The Single European Sky ATM Research (SESAR) programme represents the technological pillar of the SES initiative. It will provide new technologies, systems and procedures with a view to modernising and optimising the future European ATM network ${ }^{3}$. The SESAR programme aims to: 1) improve safety performance, 2) gain additional capacity and reduce delays, 3) enhance efficiency by reducing the costs of ATM services.

SESAR admits that, despite the need to promote the use of technology, human actors will still play a key role for implementing the new changing of the future European ATM system. No matter how advanced the concepts and systems become, the controllers, pilots, engineers, maintenance technicians and other front-line operators will continue to be a critical element to ensuring safety. In other words, despite advances in automation, human actors will be on centre stage as decision makers and new technologies should support their activities and tasks. As a consequence, HF and neurophysiological measurements will play a central role by studying and applying knowledge about the performance of operators in their working environments.

\section{The strategic research agenda for Human Factors}

Flightpath $2050^{4}$ sets out the vision for the ambitions of European aviation over the next three decades. In order to realise this vision, the Advisory Council for Aviation Research in Europe (ACARE) called on several experts from the entire Air Transportation System (ATS), and developed a roadmap called the Strategic Research and Innovation Agenda (SRIA) 5 . This roadmap lays out what is needed to be done in three timeframes (2020, 2035 and 2050) for all the five pillars of Flightpath 2050: Mobility (suitable and sustainable for passengers and freight), Competitiveness (in world air transport markets, supported by a strong research network and balanced regulatory framework, in the face of fierce competition from both established and emerging rivals),

\footnotetext{
http://www.sesarju.eu/solutions

http://ec.europa.eu/transport/modes/air/doc/flightpath2050.pdf

http://www.acare4europe.com/sria
} 
Environmental Protection (producing liquid fuels and energy from sustainable biomass), Education and Infrastructure (supported by training and simulation tools), Safety and Security (to ensure that passengers and freight as well as the air transport system and its infrastructure are protected). A special focus is laid on Human Factors: Safety and human performance are inextricably linked. The importance of integrating human performance into the system to increase its resilience and tolerance to error is vital. The human dimension needs significant attention to ensure that the future workplace, the procedures and the supporting systems will be designed for the individual, as opposed to the individual adapting to the workplace. Vigilance is maintained and systems are able to monitor, detect and correct abnormal behaviours ${ }^{6}$.

The Flightpath 2050 vision on HF is: "The occurrence and impact of human error is significantly reduced through new designs and training processes and through technologies that support decision making". A precise goal is set: "The objective is the $80 \%$ of reduction of human errors in accident causes".

In the United States (US), The Federal Aviation Administration (FAA) and National Aeronautics and Space Administration (NASA) undertake human factors research as part of their NextGen-related programs and projects to assess the envelope of human performance capabilities and limitations with new concepts and automation.

Europe and U.S. vision on the importance and role of Human Factors are more and more aligned, and in 2015 FAA and Eurocontrol jointly produced the white paper "A Human Performance Standard of Excellence"7, with the aim of helping the air traffic management industry realise better usage and integration of human performance approaches in its pursuit of excellence in business performance and Safety.

\section{E. The top 5 Human Factors Research and Innovation priorities}

In July 2014, the FP7 European project OPTICS organised a workshop to discuss major HF research needs to increase the current level of safety in aviation. OPTICS is a project funded through the European Commission with the objective of reviewing the degree of contribution of the various European ATM-related projects to the objectives of the SRIA. The workshop attracted 70 experts in HF from 17 countries across the ATS spectrum. The aim of the workshop was to ask experts to determine the major Human Factors Research \& Innovation (R\&I) priorities for aviation

\footnotetext{
${ }^{6}$ http://www.eurosfaire.prd.fr/7pc/doc/1349425601_sria_acare vol1.pdf ${ }^{7}$ http://skybrary.aero/bookshelf/books/3291.pdf
}

safety. The OPTICS workshop results ${ }^{8}$, integrated with information coming from the HF state of the art in the aviation domain, showed that the following are the top 5 HF capabilities needed.

Table 1: The top 5 Human Factors capability needs

\section{Capability Explanation}

\begin{tabular}{l|l|}
\hline 1 & Human \\
& Performance \\
& Envelope \\
& (HPE)
\end{tabular}

"Human Performance refers to the adequate performance of jobs, tasks and activities by operational personnel - individually and together"'. The envelope is a metaphor to indicate the boundaries within which the performance is good or within system tolerance. The capability of assessing if controllers are within their HPE (i.e. with an optimal level of situation awareness, workload, fatigue and so on), so capable to provide adequate performance, is considered vital both for system safety and workers' wellbeing.

Currently, for only a part of the factors composing the HPE validated assessment tools are available.

\begin{tabular}{l|l}
\hline 2 & Design and \\
& Manufacturi \\
ng
\end{tabular}

It is known that HF aspects should be taken into consideration from the early phases of design. This does not impact only on the usability, safety and utility of new systems and tools, but also on the effectiveness of the process itself, reducing costs and risks.

While there are pockets of guidance and good practice, there is no regulation on Human Factors encompassing the entire aviation transport system and its design life cycle, stating when to do $\mathrm{HF}$, with what guidance, and against which standards. A common framework is needed for integrating $\mathrm{HF}$ into the design of ATM, Avionics and Airframe systems, encompassing all system developers and users.

Adaptive Develop and test concepts of Automation adaptive automation is an approach to (AA) automation design where tasks are dynamically allocated between the human operator and computer systems [10]: both the user and the system can initiate changes in the level of automation. ATM systems are moving towards high automation to face the grown in traffic that is expected in the

${ }^{8}$ http://www.optics-project.eu/wp-content/uploads/2014/07/OPTICSWorkshop-Highlights.pdf

${ }^{9} \mathrm{https} / / / \mathrm{www}$. eurocontrol.int/sites/default/files/article/content/documents /nm/safety/hp_white_paper_2010_low.pdf 


\begin{tabular}{|c|c|c|}
\hline & & $\begin{array}{l}\text { upcoming years. } \\
\text { A better understanding of how highly } \\
\text { automated systems impact human } \\
\text { performance as well as tools able to } \\
\text { inform system about the internal state } \\
\text { of operators is vital for the design of } \\
\text { safe and effective tools as well as the } \\
\text { design of new roles and jobs for } \\
\text { controllers. }\end{array}$ \\
\hline 4 & $\begin{array}{l}\text { Monitoring } \\
\text { of crew/team } \\
\text { capacity }\end{array}$ & $\begin{array}{l}\text { Develop the capability to monitor } \\
\text { in real-time crews concerning their } \\
\text { mental state, such as workload, fatigue } \\
\text { and degradations in vigilance. This is } \\
\text { considered fundamental for the } \\
\text { prevention of safety issues related to } \\
\text { degraded individual conditions. } \\
\text { Today, there are few validated and } \\
\text { usable during operations means } \\
\text { available for the real time assessment } \\
\text { of operators capacity. }\end{array}$ \\
\hline 5 & $\begin{array}{l}\text { Training } \\
\text { design and } \\
\text { expertise } \\
\text { assessment }\end{array}$ & $\begin{array}{l}\text { Initial and ongoing training are crucial } \\
\text { (and expensive) activities to ensure } \\
\text { efficiency and safety. There is an } \\
\text { innovation gap in current training } \\
\text { approaches: trainers have few tools to } \\
\text { support their work, with assessment } \\
\text { only based on subjective assessment, } \\
\text { self-introspection and few performance } \\
\text { metrics. Both the designing of new } \\
\text { training methods and their } \\
\text { administration could greatly benefit } \\
\text { from the use of tools able to understand } \\
\text { the level of training reached by } \\
\text { operators and for which specific areas } \\
\text { they need to practice more. }\end{array}$ \\
\hline
\end{tabular}

\section{F. Human Factors evaluation by using neuroscience knowledge}

Enhancing the ability to investigate the human cognition and assess specific mental states is mandatory to address the capabilities listed above and provide reliable, simple and easy-to-use tools to the HF teams working in the ATC field.

Very recent studies in the cognitive research have demonstrated the applicability and the effectiveness of neurophysiological metrics in assessing ATCOs' mental states, such as mental workload, cognitive training, attention, vigilance, crew cooperation, cognitive control behaviour [11]-[18]. To better explain the different contributions that neuroscience could bring to the ATC domain, we present some HF gaps that could be closed thanks to the recent research results. For the sake of simplicity, we will focus on the five capabilities listed above (i.e. Human Performance Envelope, Human Factors in Design and Manufacturing, Adaptive Automation, Monitoring of crew/team capacity, Training design and Expertise assessment) and related mental states whose measurement, even in real time, could be used to close or at least reduce such HFs related gaps.

\section{1) Human Performance Envelope}

The idea behind the Human Performance (HP) envelope is that human performance is a product of many interacting factors. Some of these aspects play a role before the actual operations, as the level of training and expertise achieved. Some others factors take place while the operators are working, like, for instance, workload, fatigue, stress, situation awareness, decision making_[19]_. More generally, workload concept has been demonstrated to directly impact on the other mentioned mental states [20]. In this context, it represents the most studied mental state due to its strong relationship with the increasing or degrading of user's performance [21]. By understanding the impact of such factors on the operators' performance, specific countermeasures can be proposed, e.g. controllers can compensate accordingly, external parties or proper automations can augment human performance or take over the control. The gaps that could be addressed by the neurometrics are the following two:

- Provide objective measures of the various HP envelope factors. Current measurements are often derived from self-reports, provided by operators or observers (i.e. experts or trainers), as the NASATask Load Index (NASA-TLX) questionnaire [22], the Instantaneous Self-Assessment (ISA) technique [23], which have well known limitations [11], [15], [24], [25]. For example, they cannot follow the envelope of the task without requiring the additional activity of filling the questionnaire regularly (invasiveness) and with accurate time resolution (no real - time evaluation) Additionally, it has to be considered the biases related to their intrinsic subjective nature (operator-dependent bias). On the contrary, neurophysiological measurements of the HP envelope would be ideally carried out in realtime, to detect risky drifts towards the envelope boundary and trigger dynamic responses.

- Provide input to better understand some of the current factors composing the HP envelope. In fact, HFs are mostly rooted in cognitive psychology concepts, often based on introspection. Objective measurements could break HF concepts down into more elementary measurable cognitive processes like perception, attention, decision making.

\section{2) Human Factors in Design and Manufacturing}

Many HF issues encountered during ATC operations are currently credited to non-optimal design, resulting in limited usability, incorrect mental models, and lack of understanding of the actual work practise and context [26]. Effective HF integration could cover the design of 
all the system elements, e.g. tools, human-machine interface, procedures, roles and communication flows. In fact, it could span from detailed design elements (lights and bottoms positioning and colours), to high level aspects and decisions (assessing the cumulative workload or fatigue induced in the operator by a new sector configuration). Also, it should provide the understanding of how all these factors interact, to ensure that individual elements are designed with a systemic perspective. System designers should possess at least a basic appreciation of HF, whereas HF experts should become part of the design team due to their technology maturity.

The main gap is the lack of appropriate data to steer design and validate proposals in the $\mathrm{R} \& \mathrm{D}$ phases, as $\mathrm{HF}$ input is typically seen as highly subjective and not standardised, therefore impossible to compare across time and situations, and hard to integrate with current design and development industrial processes. Typical HF concepts used in R\&D to steer design are workload, usability, situation awareness, number and type of errors. In particular, from a cognitive point of view, objective measurement of the operator's mental workload might help in having a deeper comprehension of the advantages of alternatives designs in terms of requested cognitive resources. Quantitative information could then support and help the comparison among the different technologies in order to better identify the best choice for specific operative condition [24]. The use of neurometrics could address this gap by:

- Providing objective and standard data to compare alternatives designs [24]. Neurometric Data could also be collected after the technology has been introduced into operations, to monitor its actual use (typically to some extent different than the intended use). These data could provide valuable input for design and safety departments. The use of neurometrics in operations would also address the small sample problem, as $R \& D$ projects typically have limited budget to involve professional controllers (or operators in general). However, these aspects require a (validated) link between $\mathrm{HF}$ concepts and neurophysiological indicators.

\section{3) Adaptive Automation}

The concept of Adaptive Automation goes beyond traditional modes of human-computer interaction. It entails that the system receives information on the operators' physical and cognitive status, to then adapt its behaviour. Examples of such application are:

- Interface changes to reduce visual clutter (e.g. filtering non relevant flights), or to ease visual scanning tasks (e.g. increasing salience of alarms);
- Changes to interaction modalities to support handsfree operations or to offload the visual channel (e.g. haptic or aural feedback would be typical cases);

- Shifts in the processing logic for data filtering or decision-support, e.g. moving to a less conservative detection logic to reduce the number of non-relevant alerts being displayed.

In extreme cases, like operator's incapacitation, automation can take full control and bring the system safely to an equilibrium point. Fox example, on Mig29, F-117 and EFA2000 jetfighters there is a button called "Panic Button" by which the pilot, who is losing consciousness, can give the full control of the jet to the system and recover it to a safe configuration.

The idea of adaptive automation is not new, but to date attempts have focussed mainly on linking the status of information and functions provided on a human-machine interface to descriptors of the situation, e.g. traffic load. Only with recent advances in neurophysiology, adaptive systems that are driven by the operators' mental state have become an important research topic. In the last years, several neuroergonomic systems, that use neurophysiological measures to trigger changes in the state of automation, have been studied and their impact on operators performance analysed. [27]. Evidences show that people not only think of adaptive systems as "coworkers", they may even expect them to behave like humans.

Despite its potential advantages, adaptive automation also holds a potential pitfall. The dynamic behaviour changes of adaptive systems makes it more complex and less predictable for the user. Situations in which users are surprised and confused by "what is the system doing?" must be minimized. Some lessons can be learned from flight deck automation, most notably the introduction of first generation of glass cockpits [28], [29]. The concept of adaptive automation may hence need to be revisited or fine-tuned, to increase the operator acceptance. It may be that an intermediate stepping - stone is needed, such as adaptable automation. In this scenario, the user can trigger advanced automation at her/his discretion, avoiding confusion and retaining the sensation of being in control. Users could also regain control if things go wrong, and the automation can no longer cope with the situation. Several strategies regarding the triggering mechanism of automation have been proposed [30]. Generally, three are the main approaches described in the literature: (i) the Critical-event strategy, based on the a-priori assumption that human workload may become too high when the critical events occur [31]; (ii) the Performance-measurement strategy, based on the use of operator's performance during the task itself 
or additional ones (also called behavioural measures) to estimate current and predicted operator's state and to infer whether workload is excessive or not; (iii) Neurophysiological measurement strategy, based on the recording of operator's neurophysiological signals, e.g. electroencephalogram (EEG) to infer his actual mental workload [32], [33].

In this context, the research contribution of neurometrics could address two important issues:

- Neurometrics could define the thresholds by which to activate the transitions between the automation levels (lower or higher than the previous one). Thresholds may be binary (on-off), or more accurate along larger time windows, to avoid continuous transitions, and to consider cumulative effects. For instance, a medium-high workload level lasting for several minutes could trigger the same transition as a very high workload peak. Similarly, after a sustained period of work with high automation, the same level could be maintained for some time even with low workload to ease recovery.

- Neurometrics could provide scientific validation of the adaptive automation effectiveness, for instance by showing an actual workload decreasing after the adaptive automation intervention.

\section{4) Monitoring of crew/team capacity}

Aircraft accident investigations had revealed that $80 \%$ of accidents were based on human error, but further investigation indicated that a significant portion of human error was attributable to $\mathrm{HF}$ failures primarily associated with inadequate communication and coordination within the crew [34]. Beyond the technology and equipment progress, specific $\mathrm{HF}$ training methods (e.g. Crew Resources Management CRM) have led to the reductions of aviation accidents. In fact, since the end of 90s, CRM training has been required for all military and commercial US aviation crews and air couriers [35]. The general concept of crew team capacity monitoring is based on the use of smart technologies to monitor in real time signs of possible operators impairments, such as drowsiness, fatigue, excessive workload, or degradation of vigilance [18]. Detection should be done in real-time, to enable correction by the crew and/or by the system itself. Monitoring of team capacity is closely linked to the HPE concept, as the choice of what to monitor derives from the envelope definition. Current works are mainly directed to workload and to cases of physical incapacitation (e.g. hypoxia) measurement [36]. The Advisory Council for Aviation Research and innovation in Europe (ACARE) expects, as an objective to achieve within the 2020, the employment of technologies in aviation able to measure and correct/prevent in realtime overload situations ${ }^{10}$.

The research contribution of neurometrics is to develop objective indexes to detect such conditions (i.e. overload situations), and to customise these indexes to the various aviation scenarios in operational environments and during training activities.

\section{5) Expertise assessment}

Even when indications are given, the feedback may not be detailed enough to understand which skill is still lacking. Is it a manual skill or cognitive demanding process? Trainers mostly rely on their experiences in "reading" Trainees' cues, or on Trainees' selfperception.

Moreover, Trainees sometimes fail the exam mostly because of poor stress management, not because of lack of skills. The cost of a failed test can be extremely high, for instance in those curricula where the Trainee can only take the final exam twice or three times. If the Trainee fails, the whole investment made on her/him will be lost.

Finally, the workforce must receive appropriate training to perform safely and effectively with the new automated solutions that will be implemented in the near future ${ }^{11}$. This includes regular training on fallback procedures to ensure competency in the event of system failure and to prevent the degradation of skills needed in such an event. This is relevant both for the training of new controllers and for the transition of current professionals to new systems during their career. For such a reason, there is the necessity of objectively monitoring and assessing operators' performance [37], especially in terms of cognitive resource and brain activations [15].

Neurometrics can play a key role for this capability, providing an objective measure of the training progresses of the Trainee or the Operator [13], [38][40]. Such information could be very useful for the Trainer, supporting him during his evaluation activity. Such improvement in the training evaluation should produce:

- Increased Efficiency: Trainees can devote less time to topics already mastered, and focus more on topics they find hard-to-learn;

- Training Personalisation: Trainers will acquire clear and objective feedback on how each Trainee is progressing. Such data can be used to define ideal personalised learning paces for each Trainee;

\footnotetext{
${ }^{10} \mathrm{http}: / / \mathrm{www}$.acare4europe.com/new-crew-and-team-concepts-19

${ }^{11} \mathrm{https} / / /$ publicapps.caa.co.uk/docs/33/CAP\%201377\%20final\%20Mar\% 202016.pdf
} 
- Avoidance of Unnecessary Fails in Final Tests: Trainees sometimes fail an exam mostly because of poor stress management, not because of lack of skills. Neurometrics can help to single out the causes, by measuring the stress level during the training, or during the test. Dedicated stress management training can then be organised to address the events where the stress impacts strongly on the Trainee's performance.

\section{NEUROPHYSIOLOGICAL MEASURES: CURRENT STATE-OF-THE-ART}

In the previous section, the top five HF needs in the ATC domain have been widely discussed. In this regards, we reported some practical applications of the neuroscience, stressing its importance for the future development of the ATC system.

In this part of the paper, we present some important results with the aim of showing the progresses that have been made on the possibility to measure HF concepts by using neurometrics, and the possibility to develop and use specific tools in the ATC work environment. The concepts at the basis of the HFs described previously are mainly two:

- Mental workload;

- Training and Expertise.

These aspects represent clear examples of fundamental topics and crucial issues within the ATC domain. Their objective evaluation would directly influence the top-5 capabilities presented before. For example, workload (together with fatigue) is involved in the human performance envelope, error prevention of operators, design of new tools and systems and triggering of adaptive automation solutions. Moreover, training and expertise are key factors not only at the beginning of the ATCOs' careers, but throughout all their work experience, therefore they have to be periodically checked.

\section{A. Which neurometric to be used for the investigation of the HF concepts?}

In recent decades, neuroscience has been focusing on the evaluation of user's mental states in operational environments, by means of neurophysiological signals. Neuroscientific researches are based on the use of neuroimaging technologies and neurophysiological measures, including Electroencephalography (EEG), functional Near-InfraRed (fNIR) imaging, functional Magnetic Resonance Imaging (fMRI), Magnetoencephalography (MEG), and other types of biosignals such as Electrocardiography (ECG), Electrooculography (EOG) and Galvanic Skin Response (GSR) [41]-[43]. Neuroimaging methods such as Positron Emission Tomography (PET) and
fMRI are excellent tools in this endeavour, enabling the examination of how the brain adapts itself in response to practice or repeated exposure to particular tasks. However, their limitations in terms of cost, space and invasiveness make them not suitable for real working environment settings, where a less invasive approach would be preferable and the costs for its implementation and usage has to be limited. In fact, PET and fMRI techniques require expensive instruments and high maintenance costs, In addition, fMRI [44] and MEG techniques require room-size equipment that are not portable. On the other hand, EOG, ECG and GSR activity measurements highlighted a correlation with some mental states (stress, mental fatigue, drowsiness), but they were demonstrated to be effective only in combination with other neuroimaging techniques directly linked to the Central Nervous System (CNS), i.e. the brain [40], [41], [45]. Furthermore, it has been showed in few works as brain signals recordings (i.e. EEG) represents the best performing information in mental states evaluation in respect to other peripheral physiological signals (i.e. EOG, ECG, GSR, [46]). In this regard, EEG and fNIRs are the most likely candidates that can be straightforwardly employed to investigate human brain behaviours in operational environments. The propensity for using EEG or fNIRs techniques has not been clarified yet. There are several factors to take into account about real operational scenarios. For example, both EEG and Fast Optical Signal (FOS)-based fNIR have similar bandwidth and sample rate requirements, as the FOS appears to directly reflect aggregated neural spike activity in real-time and can be used as a highbandwidth signal akin to EEG [47]. However, EEG and fNIRs systems have different physical interfaces, sizes, weights and power budgets, thus different wearability and usability in real operational contexts. In this regard, the presence of hair may impact negatively on both photon absorption [48] and the coupling of the probes with the underlying scalp, thus the fNIRs technique is very reliable only on those un-hairy brain areas, like the Pre Frontal Cortex (PFC). For the mental states investigation, also other cortical regions, such as the parietal brain sites play an important role. Derosière et al. [49] pointed out how some fNIRs-measured hemodynamic variables were relatively insensitive to certain changes during the brain activity. In conclusion, due to its higher temporal resolution and usability, in comparison with the fNIRs technique, the EEG technique overcomes such issues related to the fNIRs and appears as the better candidate for such kind of applications in the operational environments, and in particular in the ATC domain. 


\section{B. Mental states evaluation by neurophysiological approach}

As stated before, two mental states are the most important to focus our attention on:

- the mental workload experienced by the operator during working activities;

- the training level and expertise degree of operators.

In the following, the two mental states will be discussed in order to better understand their correlation with neurophysiological reactions, in particular in terms of brain activity.

\section{1) Mental workload}

The mental workload monitoring is of particular interest especially in safety-critical applications where human performance is often the least controllable factor. In fact, as the mental workload increases, it became harder to maintain the user's task performance within an acceptable range, resulting then into an increasing of errors' occurrence. Focusing on the aviation domain, for example, the Aviation Safety Network reported 19 accidents with 960 casualties during the last years; in many cases factors related to workload, situation awareness and monitoring were a cause or contributing factor. Consequently, ensuring that operator performance remains within the performance envelope is of greatest importance, and reliable indicators measures of cognitive activity and related states such as mental workload and situation awareness are of great interest.

Cognitive psychology literature demonstrated that the mental workload has an "inverted U-shape" relationship with performance. In other words, some levels of mental workload may help the user to reach high performance level [50], since it stimulates positively the user and it keeps him/her awake with high attention level. On the contrary, a period of mental inactivity and "under-stimulation" can cause a monotonous and boring state (underload), a low level of vigilance and attention, with low cognitive resources demand. Additionally, an operative condition characterized by demanding multi-tasks can lead the user to an overload condition and to a likely occurrence of errors [51].

It is difficult to give a unique definition of mental workload. Various definitions have been given during the last decades, for example:

- "Mental workload refers to the portion of operator information processing capacity or resources that is actually required to meet system demands" [52]

- "Workload is not an inherent property, but rather it emerges from the interaction between the requirements of a task, the circumstances under which it is performed, and the skills, behaviours, and perceptions of the operator" [22];

- "Mental workload is a hypothetical construct that describes the extent to which the cognitive resources required to perform a task have been actively engaged by the operator" [53];

- "The reasons to specify and evaluate the mental workload is to quantify the mental cost involved during task performance in order to predict operator and system performance" [54].

These definitions show how the mental workload may not be a unitary concept because it is the result of different aspects interacting with each other. In fact, several mental processes can be involved in every situation and these are a function of the demands of various sub-tasks.

In the mental workload related literature, psychophysiological measurements are often used to evaluate the level of cognitive demand induced by a task [55], [56].

In particular, characteristic changes in the EEG spectra reflecting levels of mental workload have been identified in different works [57]-[61]. Several studies described the correlation of spectral power of the EEG with the complexity of the task that the subject is performing. In fact, an increase of the theta band spectral power $(4-7(\mathrm{~Hz}))$, especially on the frontal cortex, and a decrease in alpha band (8-12 (Hz)), over the parietal cortex, have been observed when the required mental workload increases [41], [61]. In this regard, Smith et al. [62] recorded continuous EEG while 16 participants were performing specific computer-based flight simulation task, the MultipleAttribute Task Battery (MATB; [63]), under low, moderate and high difficulty. As the task difficulty increased, the frontal midline theta EEG activity increased while parietal midline alpha decreased. In such research field, Wilson [64] reported a study involving ten pilots who performed an approximately 90-minutes flight simulation scenario, containing both visual and instrumental stimuli and different flight conditions. Multiple variables including EEG parameters were analysed. Wilson [64] found that parietal alpha band showed significant reduction under high workload condition, but an increasing in the theta power spectrum could only be observed on few electrode sites. Workload can be influenced by different factors, such as variations of alertness and vigilance, mental fatigue, mental effort, complexity of the task, attentional variations and drowsiness [65], so it is fundamental to establish a valid method for the mental workload measurement. Furthermore, several mental processes are affected by such factors. Thus, the neurophysiological measurements of the mental 
workload (even in real-time) could become very important, not only as monitoring techniques, but especially as supporting tool for the user during operational activities. In fact, as the changes in cognitive activity can be measured in real - time, it is possible to manipulate the task demand by adapting the user interface in order to help the user in keeping optimal levels of mental workload (and performance). In this regard, different methodologies have been proposed to evaluate mental workload by using neurophysiological (i.e. EEG) measurements. Many works combined EEG features related to workload for a reliable neurophysiological index, for example, by using the ratio between power bands [66]-[68]. Pope et al. ([67]), who reported the first brain-based adaptive system, established a model to measure the task engagement based upon ratios of EEG power bands. Borghini et al., [24] proposed a study in which a workload index, calculated as the ratio between frontal theta and parietal alpha power bands, has been used to compare different avionic technologies from cognitive demand point of view.

Another approach towards real-time assessment of mental workload is to use machine learning approaches, e.g. linear discriminant analysis (LDA), support vector machine (SVM), artificial neural network (ANN), etc. Several studies classified workload into different levels by using EEG features in either a simple, single-task [69], [70] or complex tasks with skilled operators [71][73]. The use of the machine learning techniques allows to assess the subject's mental workload in a short time (i.e. few seconds) reaching a high accuracy (>90\%). Another interesting approach regarding the real-time mental workload evaluation has been explored by Dimitriadis and colleagues [74], who proposed a novel functional connectivity-based approach. In particular, they used a Tensor Subspace Analysis (TSA) to represent connectivity data, achieving a high correctrecognition-rate $(\sim 96 \%)$ of difficulties in an arithmetic task by using a k-NN classifier. In the following, the application of neurophysiological measurements for the mental states evaluation in ATM environment will be reported.

\section{2) Mental workload in ATM}

Different studies showed the possibility to assess the ATCO's mental workload by using the brain activity (EEG signal). In this regard, in the last decade the EEG has been highlighted to be the most reliable neurophysiological measure related to mental workload. For example, Brookings et al. [14] have investigated the mental workload changes, associated with variations in difficulty levels of Terminal Radar Approach Control (TRACON), in a simulated ATM, on 8 military ATCOs. The task included multiple measures such as performance, subjective and physiological metrics to evaluate the changes in controller workload. The results showed that the effects of the difficulty level were particularly evident in the theta band power, at central, parietal, one frontal and one temporal brain sites, since it showed significant increases as the task difficulty increased, and in the alpha band, where the activity decrement was influenced by the interactions between the difficulty level and traffic manipulations. The results obtained by Brookings et al. [14] are consistent with those reported by the other studies using similar indexes in ATC. For example, in a recent study, authors [75] tried to evaluate mental fatigue and workload during an ATC experiment using a time-frequency Independent Component Analysis (tfICA) method. They found that "the frontal theta EEG activity is a sensitive and reliable metric to assess workload and time-on-task effect during an ATC task at the resolution of minute(s)". Moreover, they showed "the potential capability of tfICA method in probing neural activations from continuous EEG in real world tasks". In several very recent studies involving professional ATCOs and trainees, it has been demonstrated how, by using machine-learning techniques and brain features extracted from EEG data, it is possible to compute a brain Workload Index able to significantly discriminate various ATM tasks on the basis of their difficulty level [11], [32]. Moreover, in another study this index was able to evaluate the impact of different avionic technologies on the mental workload of helicopter's pilots [24]. Furthermore, it has been demonstrated that such kind of Workload Index can be used as a reliable measure of the mental workload experienced by an ATCO also in ecological working scenario, where the difficulty of the task has not a discrete, but a continuous, profile [15], [76]. In particular, in this study six professional ATCOs had to perform an ecological ATM task by using the eDEP software, a validated simulation platform developed by EUROCONTROL. In a similar study, twelve professional ATCOs have been asked to manage simulated high realistic ATM scenarios under different difficulty levels [11]. In order to simulate a realistic situation, tasks were developed with a continuously varying difficulty level, i.e. starting form an easy level, then increasing up to a harder one and finishing with an easy one again. The EEG-based mental workload index was shown to be directly and significantly correlated with the actual mental demand experienced by the operator during the whole task, and collected by using the ISA technique. Finally, in a very recent study authors proposed an EEG-based system able to trigger Adaptive Automation (AA) solutions integrated in a realistic ATM research simulator hosted at the École Nationale de l'Aviation Civile (ENAC, Toulouse, France) depending on the actual measured mental workload of the operator. The system has been tested on twelve ATCOs, while performing high- 
realistic ATM scenarios at different difficulty levels. Results of the study demonstrated the effectiveness of the proposed system, since it enabled the AA mostly during the high-demanding conditions (i.e. overload situations) inducing a reduction of the mental workload under which the ATCOs were operating. On the contrary, as desired, the AA was not activated when workload level was under the threshold, to prevent too low demanding conditions that could bring the operator's workload level towards potentially dangerous conditions of underload [32] (Figure 1).

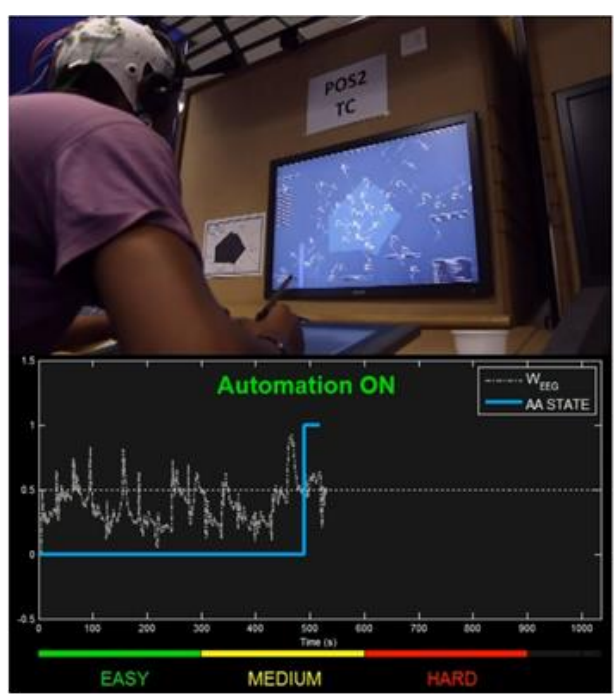

Fig. 1. It has been reported a real experience of how an EEG-based workload index (WEEG) can be used to trigger Adaptive Automation (AA) solutions embedded within an ATM simulator hosted at the Ecole Nationale de l'Aviation Civile (ENAC, Toulouse, France).

In all these studies, [11], [12], [15], [25] the brain features related to the mental workload were sought within the frontal theta, parietal alpha and occipital theta rhythms. Also, the BOLD signal of the fNIR technique has been demonstrated to be a reliable indicator of the ATCO's workload. For example, in two recent studies [77], [78], the fNIR technique has been investigated in the ATM sector. Based on the hypothesis that the hemodynamic response (i.e. rapid increase in the blood delivery to active neuronal tissue) over the PFC was responsive to mental workload, i.e. greater workload is consistently associated with greater cortical activation, in a realistic command and control task [79], [80], Ayaz et al. [78] demonstrated how the BOLD signal is a reliable workload index: in fact by using this index, it was possible to discriminate significantly the different workload requested by two different communication types (Data and Voice), on 24 professional ATCO. Furthermore, Ayaz et al. [77] showed that fNIR can be successfully used in ecologically valid environments to assess: 1) mental workload levels of ATCOs performing standardized (nback) and complex cognitive tasks, and 2) expertise development through learning a complex cognitive and visuo-motor tasks in Unmanned Aerial Vehicles (UAV) pilots.

\section{Training and Expertise}

Technological developments are changing the nature of ATC activity, and shifting emphasis from skilledbased to knowledge-based behaviours are bringing to select new types of skill set [81], [82]. Skill-based behaviours are highly-practiced, and often semiautomatic ones that occur in highly familiar situations [83]-[85]. A large portion of the expert controller's behaviour is skill-based. Knowledge-based behaviour (like problem solving), on the other hand, are necessary in novel situations, when the accustomed skills are ineffective [83]-[85].

Controllers in future will be confronted with the combined requirements to handle more air traffic, to use new methods of data presentation and handling, and use new automated aids. These developments are likely to have a considerable influence on the abilities demanded of the future controller.

In fact, some aptitudes that are usually important, now they will become more important, whereas some will become less important in the future [86] ${ }^{12}$ :

- Scanning (of visual sources), Perceptual Speed and Accuracy, Translating Information, Chunking, and Interpreting Information will increase in importance to achieve successful performance in ATM, in terms of aptitudes relating to acquiring information ("input").

- From a "process" perspective, the importance of attention and memory aptitudes, such as Sustained Attention, Recall from Interruption, Situational Awareness, and Long-Term Memory, for successful job performance will increase in the mid-term. The increase in the importance of Sustained Attention and Recall from Interruption is driven by the projected increases in ATC operations. The increase in the importance of Situational Awareness and Long-Term Memory is coupled to the tools needed to handle the increase in traffic (e.g. Decision Support Tool-DST).

- Problem Identification and Prioritization will become more complicated and more important in the mid-term, depending on the transparency, operational acceptability and reliability of the ATCO-supporting toolslsystems. The importance of the aptitudes Time-Sharing, Information Processing Flexibility, and Task Closure/Thoroughness will

${ }^{12}$ https://www.faa.gov/data_research/research/med_humanfacs/oamtechr eports/2010s/media/201305.pdf 
increase with both traffic and the implementation of supporting tools

- Two new aptitude requirements were identified in the mid-term: Dispositional Trust in Automation and Computer Human Interface (CHI) Navigation.

- In terms of "output," the importance of the aptitude Manual Dexterity (in using a keyboard, mouse, touch screen, and/or numeric keypad) will depend on the actual $\mathrm{CHI}$ implementations but is likely to increase.

Whereas specific skills have been essential so far, what is likely more important in future are more generalised knowledge about system dynamics, decision making and diagnosis and problem solving skills, driven largely by the introduction of advanced automation. This is certainly a concern in ATM, in which the advent of advanced automated tools (especially strategic aids like the Multi Strategic Platform - MSP, [87]) forced a rethinking in the types of skills for which controllers should be selected [88], [89], the roles of the executive and planner controllers become more inter-twined, and teamwork becomes more of a concern. Some have focused attention on providing automation-specific training [80], [90]. Such new ATM concepts and demanded new skills will have significant implications for the selection and training of ATCOs. Furthermore, new training procedures will have to be developed to turn a controller accustomed to positive control of the airspace into a "manager by exception" [91]-[94]. One of the greater overarching trends in recent training research appears to have been the increased attention paid to individual learning styles [95], [96]. Rather than a passive "one-size fits-all" approach, the so-called Learner-Directed Training [97] process relies on the trainee to be more active in the process of On the Job Training (OJT), as in soliciting feedback, asking technical questions, etc. One final training trend seems to have been the increased use (or interest in) emerging technologies, such as Virtual Reality (VR), Expert Systems, and so-called Electronic Performance Support Systems, or EPSSs [98]. Recent advances in technology have made such systems feasible (or almost feasible) in the operational training settings. They can serve either as a direct training tool (perhaps letting trainees learn from simulation), or as a means of augmenting training - for instance by offloading the routine (e.g. data retrieval) tasks and allowing the trainee to better focus on the salient and critical aspects of training.

The main limitation of standard methods for the training assessment is the lack of objective and quantitative information about the requested cognitive resources during the execution of the proposed task. In fact, the learning progress of trainees is generally evaluated by the supervision of experts and/or by asking the trainees to fill questionnaires with the aim to gather information on the workload or difficulty perception of the considered task. It is easy to understand how such methods are highly operatordependent, and how experience and emotions, both for the expert and trainees, could affect the evaluation of the training. To overcome such limitation, it is necessary to analyse the cognitive processes and consequences involved when learning to execute correctly a new task. In this regard, even if task performance data are available, this could not be enough to assess a comprehensive training profile of the operator. For example, although the results in terms of performance should be the same, the cognitive demand for the same operator could be not. In other words, after a certain time the operator should still be able to execute the same task by achieving the same performance level, but it might require less amount of cognitive resources. Therefore, different operators could achieve the same results, but involving a different amount of cognitive resources (Figure 2).

\begin{tabular}{l|c|c|} 
TRAINING SESSIONS & 1 & 2 \\
\hline $\begin{array}{l}\text { LEVEL OF TRAINING } \\
\text { (trainee 1) }\end{array}$ & \\
\hline $\begin{array}{l}\text { OVER TASK } \\
\text { PERFORMANCE LEVEL } \\
\text { (trainee 1) (trainee 2) }\end{array}$ & \\
\hline
\end{tabular}

Fig. 2. The graph shows an example of training assessment of students from a cognitive point of view, with respect to task performance alone, along a training program. In particular, although the two trainees reached the same task performance level across the training sessions, the trainee 1 needed one more training session then the other operator, since cognitive resources used to accomplish the task were still too much high. On the contrary, the trainee 2 reached already at the 2nd session the highest performance level, together with the lower amount of cognitive resources employed.

When presented with a new task, an individual will acquire a level of expertise most efficiently by utilizing the most effective mode of practice and/or spending more time engaged in the task. Natural abilities contribute to the pace of the individual's improvement and they will determine individual differences in each individual's progression toward obtaining expertise in a specific course of training. There is an extensive literature regarding the effect of practice and expertise 
on the functional anatomy of task performance. The development of expertise has been studied across a wide range of motor, visuo-motor, perceptual and cognitive tasks, and from disparate research perspectives [99]. Four main patterns of practice-related activation change have been identified in literature [100]-[102], including either 1) increased or 2) decreased activation in the brain areas involved in task performance, or, 3) a functional redistribution of brain activity, in which some initial areas of activation increase while others decrease, or 4) a functional reorganization of brain activity, in which the pattern of increasing and decreasing activation occurs across distinct brain areas in addition to the initial areas. According to Petersen et al. [103] a set of attention and control areas of the brain (the scaffolding) is used to support or cope with novel demands during unskilled, effortful performance. With practice, processes or associations that can be more efficiently stored and accessed elsewhere are offloaded to those areas, after which the scaffolding network is pruned away. Decreased reliance on the 'scaffolding' is demonstrated by decreased activation in those areas during performance with a concomitant increase in activation brain areas underlying the task-specific processes. Therefore, activations seen earlier in practice involve generic attentional and control areas. Prefrontal cortex (PFC), anterior cingulate cortex (ACC) and posterior parietal cortex (PPC) are thought to be the predominant constituents of the scaffolding consistent with theories of PFC function and the involvement of these areas in the distributed working memory system [104]. Increases brain activities associated with highly practiced performance are primarily seen in taskspecific areas such as representational cortex primary and secondary sensory or motor cortex, or in areas related to the storage of those representations, such as the parietal or temporal cortex. A majority of the studies examining task practice have found decreases in the extent or intensity of activations with ongoing practice, particularly in the attention and control areas [101], [105], [106]. Decreases in activation are thought to represent a contraction of the neural representation of the stimulus [107] or a more precise functional circuit [108]. These evidences suggest that overall, both practice and the development of expertise typically involve decreased activation across the attention and control areas, particularly in prefrontal and frontal brain areas [77], [106], [109], [110]. Some studies performed in laboratory settings have been designed to explore the possibility to track training-related changes by using biomarkers based on EEG activity. Most of them are based on spectral properties of EEG signals or Event Related Potentials (ERPs), and the extracted features are often subjected to cutting-edge mathematical tools based on machine learning theory to discriminate mental states [111]. For example, changes in P300 ERP amplitude as well as in Delta and Alpha EEG power bands have been highlighted during a complex game learning, due to changes in attentional processes along the training [112]. In addition, frontal EEG Alpha power during early phase of the game training anticipated following learning rates [113]. An interesting study performed by Taya and colleagues [114], [115], proposed a method for cognitive training assessment by using brain network analysis, the brain connectome approach [116]. Since the brain is a complex network consisting of a huge number of brain patterns devoted to different functions, it has been suggested that cognitive functions emerged from the dynamic interactions of the distributed areas in large-scale network, not a result of an activation of a single brain region [117]. In particular, such method has been demonstrated to be able to provide valuable biomarkers for monitoring and discriminate different mental states across training.

\section{3) Training assessment in the ATM domain}

Regarding the ATM context, recent studies demonstrated that measuring ATCOs' brain activation relative to task performance can provide an index of i) the level of training across the different sessions [39] and of ii) the expertise within the considered training session [109]. Such a relative quantification of the attentional and control resources necessary to perform at a given level could also serve as an index of the trainee's Cognitive Spare Capacity, that is the capacity that can be used to perform effectively under greater situational demands or unexpected events (e.g. emergencies situations).

In addition, Borghini et al. [40] and Aricò et al. ([11], [38]) demonstrated that it was possible 1) to track online the learning progress of professional ATCOs by means of a machine - learning approach across a period of a month without recalibrating the classification algorithm. Furthermore, the same authors proposed an EEG-based algorithm able to assess the operators' cognitive control behaviours accordingly to the skillrule-knowledge (SRK) taxonomy. The algorithm has been tested on thirty-seven professional ATCOs, while performing high-realistic ATM scenarios. Results of the study demonstrated that specific brain features could characterize and discriminate the different SRK levels, therefore enabling an objective assessment of the degree of cognitive control behaviours in realistic setting [109], [118].

As quoted previously, the emerging wearable brain recording technologies (e.g. EEG) can help to measure and to quantify the cognitive status and capacities of the trainee during the execution of the work in operational settings in order to provide such objective metrics directly driven by brain-based measures [119]-[121]. 


\section{DISCUSSION}

In this review, we provided the current state-of-theart of the research and application of neurophysiological measurement for the assessment of the most relevant Human Factors in the ATC field. All the evidences point to a real opportunity to establish a link between HFs involved in ATC and psychophysiological indicators. Such a linkage would go a long way in promoting innovative ATC system development. Despite of the evident benefit that neurometrics integration could have on $\mathrm{HF}$ research area, two gaps still need further investigation:

- The invasiveness of sensors, which need to be accepted by the Controllers and used during normal operations. Miniaturisation and minimal invasiveness are two key requirements. In this regards, several improvements have been done in terms of invasiveness of the measuring instruments. For example, Aricò et al., [11] proposed a machine learning technique able to evaluate the workload of the ATCO, even in real-time, by using a light EEG configuration (e.g. 2 or 3 electrodes). In addition, several industries are working on the development of reliable dry EEG electrodes, that do not require gel or saline solutions to reduce impedance between electrodes and brain skin, and considerably reduce the time of the EEG cap setup procedure.

- Understanding the time dimension of human actions from the point of view of neurometrics. For some concepts, for example workload, detection of workload peaks and triggering of adaptive automation solutions can happen in real-time. On the other hand, it can be decided to delay the adaptive automation intervention to keep the situation stable for Controllers, in order to avoid mode transitions in high workload moments. Fatigue may profit instead from detection before the work starts, as intervention at this stage can be much more effective. In short, different triggering mechanisms and time frames should be considering, depending on HF dimension being monitored, but also on the neurometrics being used.

It has however to be highlighted that, even if cognitive processes can be observed via neurometrics indicators, their interpretation requires an understanding of the context, i.e. the task and situational parameters. A combination of various indicators may be required in most situations; for example identifying the visual scan via eye movement tracking (for example dwelling on an aircraft symbols on the radar screen) whilst at the same time identifying the cognitive process (for example visual attention) could allow interpreting the controller's action.

\section{CONCLUSION AND FUTURE DIRECTIONS}

Several cognitive states have been discussed and taken into account, specifically for the ATC context. We have also discussed how mental workload, expertise and training are key HFs aspects involved in this operational environment.

Attempts of linking cognitive states to psychophysiological indicators have been partly successfully addressed, most notably in the area of mental workload and training assessment. A complete framework based on the combination of operators' biosignals, that would allow a reliable tracking of all mentioned cognitive states, has yet to be developed.

The state of the art presented demonstrates the feasibility and usefulness of the application of neurophysiological indexes in the ATC domain, in order to achieve a better understanding of human behaviour and to foresee and support it in this complex, technology-based domain. Based on the previous assumptions, two scenarios of application of neurometrics in ATC, especially of mental workload evaluation, have been outlined both in a short and a long term.

In the short term, neurophysiological measurements research is expected to directly contribute to Human Performance Envelope and Monitoring of crew capacity. The goal is to detect issues before they could cause any problem. In fact, US data from 2009 to $2014^{13}$ show how much aviation safety is impacted by disruption of human performance: $4 \%$ of incidents can be directly related to fatigue monitoring, $18 \%$ of incidents to excessive workload, $23 \%$ to operators' distraction, $34 \%$ to confusion, $56 \%$ to lack of Situational awareness. The main advantages of neurometrics would be:

- Early detection and possibly mitigation of factors negatively impacting on performance;

- More reliable data, collected ongoing the operational activities, to better understand the causes of human performance degradation. In fact, the statistics collected so far are related to self-reports (subjective data), and the variability of the measures could be very high and in some cases even unreliable due to operator biases.

In the long term, the research on neurometrics in aviation is expected to enhance Human Factors in Design and Manufacturing, Training and Expertise Assessment and Adaptive Automation. These three capabilities aim to close the loop between HF aspects and operations. HF in Design, by informing the design

${ }^{13}$ https://www.faa.gov/about/office_org/headquarters_offices/ato/service units/safety/media/ato-2014-safety-report.pdf 
with HF measurements, to inform changes and design choices; HF in Training and Expertise Assessment, by a new objective evaluation methodology, i.e. neurometrics, to support the Trainer's activity; Adaptive automation, by triggering system adaptation in real-time.

\section{ACKNOWLEDGMENT}

This work is co-financed by EUROCONTROL on behalf of the SESAR Joint Undertaking in the context of SESAR Work Package E - NINA research project (www.nina-wpe.eu) and in part by the European Commission by Horizon2020 project HCO-06-2015, "SmokeFreeBrain", GA n. 681120. The grant provided by the Italian Minister of University and Education under the PRIN 2012, GA n. 2012WAANZJ scheme to F.B. is also gratefully acknowledged. In conclusion, the authors wish to thank Sonja Straussberger for her useful comments and suggestions.

\section{REFERENCES}

[1] M. W. Scerbo, "Adaptive Automation," in The Brain at Work, Neuroergonomics., 2006.

[2] F. Aloise, P. Aricò, F. Schettini, S. Salinari, D. Mattia, and F. Cincotti, "Asynchronous gazeindependent event-related potential-based braincomputer interface," Artif. Intell. Med., vol. 59, no. 2, pp. 61-69, Oct. 2013.

[3] F. Aloise et al., "Advanced Brain Computer Interface for Communication and Control," in Proceedings of the International Conference on Advanced Visual Interfaces, New York, NY, USA, 2010, pp. 399-400.

[4] G. Di Flumeri et al., "EEG Frontal Asymmetry Related to Pleasantness of Olfactory Stimuli in Young Subjects," in Selected Issues in Experimental Economics, K. Nermend and M. Latuszyńska, Eds. Cham: Springer International Publishing, 2016, pp. 373-381.

[5] A. Riccio et al., "Hybrid P300-Based BrainComputer Interface to Improve Usability for People With Severe Motor Disability: Electromyographic Signals for Error Correction During a Spelling Task," Arch. Phys. Med. Rehabil., vol. 96, no. 3, Supplement, pp. S54-S61, Mar. 2015.

[6] R. Parasuraman, T. B. Sheridan, and C. D. Wickens, "A model for types and levels of human interaction with automation," IEEE Trans. Syst. Man Cybern. Part Syst. Hum., vol. 30, no. 3, pp. 286-297, May 2000.

[7] P. Bert, "La Pression Barométrique," Paris, 1878.

[8] D. Meister, The History of Human Factors and Ergonomics, 1 edition. Mahwah, N.J: CRC Press, 1999.

[9] R. Parasuraman and M. Rizzo, Neuroergonomics: The Brain at Work, 1 edition. New York: Oxford University Press, 2008.
[10] E. A. Byrne and R. Parasuraman, "Psychophysiology and adaptive automation," Biol. Psychol., vol. 42, no. 3, pp. 249-268, Feb. 1996.

[11] P. Aricò, G. Borghini, G. Di Flumeri, A. Colosimo, S. Pozzi, and F. Babiloni, "A passive Brain-Computer Interface (p-BCI) application for the mental workload assessment on professional Air Traffic Controllers (ATCOs) during realistic ATC tasks," Prog. Brain Res. Press, 2016.

[12] P. Aricò et al., "ATCO: Neurophysiological Analysis Of The Training And Of The Workload," Ital. J. Aerosp. Med., vol. 1, no. 12, Jan. 2015.

[13] G. Borghini et al., "A neurophysiological training evaluation metric for Air Traffic Management," in 2014 36th Annual International Conference of the IEEE Engineering in Medicine and Biology Society (EMBC), 2014, pp. 3005-3008.

[14] J. B. Brookings, G. F. Wilson, and C. R. Swain, "Psychophysiological responses to changes in workload during simulated air traffic control," Biol. Psychol., vol. 42, no. 3, pp. 361-377, Feb. 1996.

[15] G. Di Flumeri et al., "On the Use of Cognitive Neurometric Indexes in Aeronautic and Air Traffic Management Environments," in Symbiotic Interaction, vol. 9359, B. Blankertz, G. Jacucci, L. Gamberini, A. Spagnolli, and J. Freeman, Eds. Cham: Springer International Publishing, 2015, pp. 45-56.

[16] G. Durantin, J.-F. Gagnon, S. Tremblay, and F. Dehais, "Using near infrared spectroscopy and heart rate variability to detect mental overload," Behav. Brain Res., vol. 259, pp. 16-23, Feb. 2014.

[17] D. H. Goldberg, R. J. Vogelstein, D. A. Socolinsky, and L. B. Wolff, "Toward a Wearable, NeurallyEnhanced Augmented Reality System," in Foundations of Augmented Cognition. Directing the Future of Adaptive Systems, vol. 6780, D. D. Schmorrow and C. M. Fidopiastis, Eds. Berlin, Heidelberg: Springer Berlin Heidelberg, 2011, pp. 493-499.

[18] J. Toppi et al., "Investigating Cooperative Behavior in Ecological Settings: An EEG Hyperscanning Study," Accept. Publ. Plos One, 2016.

[19] I. Graziani et al., "Development of the Human Performance Envelope Concept for Cockpit HMI Design," in HCI-Aero 2016 International Conference on Human-Computer Interaction in Aerospace, PARIS, France, 2016.

[20] M. B. Weinger and J. Slagle, "Human Factors Research in Anesthesia Patient Safety," J. Am. Med. Inform. Assoc. JAMIA, vol. 9, no. 6 Suppl 1, pp. s58s63, 2002.

[21] C. D. Wickens, "Processing resources in attention," in Varieties of attention, R. Parasuraman and R. Davies, Eds. Orlando: Academic Press, 1984, pp. 62102.

[22] S. G. Hart and L. E. Staveland, "Development of NASA-TLX (Task Load Index): Results of Empirical and Theoretical Research," in Human Mental 
Workload, vol. 52, North-Holland, 1988, pp. 139183.

[23] B. Kirwan, R. Scaife, and R. Kennedy, "Investigating complexity factors in UK air traffic management," Hum. Factors Aerosp. Saf., vol. 1, no. 2, 2001.

[24] G. Borghini et al., "Avionic technology testing by using a cognitive neurometric index: A study with professional helicopter pilots," in 2015 37th Annual International Conference of the IEEE Engineering in Medicine and Biology Society (EMBC), 2015, pp. 6182-6185.

[25] G. Di Flumeri et al., "Mental workload evaluation of ATCOs during ecological ATM scenarios," Ital. J. Aerosp. Med., vol. 1, no. 13, Jul. 2015.

[26] A. Wise, V. D. Hopkin, and D. J. Garland, Handbook of Aviation Human Factors, Second Edition. 2009.

[27] E. de Visser and R. Parasuraman, "Adaptive Aiding of Human-Robot Teaming Effects of Imperfect Automation on Performance, Trust, and Workload," J. Cogn. Eng. Decis. Mak., vol. 5, no. 2, pp. 209-231, Jun. 2011.

[28] N. B. Sarter, D. D. Woods, and C. E. Billings, "Automation Surprises," Handb. Hum. Factors Ergon., 1997.

[29] N. B. Sarter and D. D. Woods, "Pilot Interaction With Cockpit Automation: Operational Experiences With the Flight Management System," Int. J. Aviat. Psychol., vol. 2, no. 4, pp. 303-321, Oct 1992.

[30] M. W. Scerbo, F. G. Freeman, and P. J. Mikulka, "A brain-based system for adaptive automation," Theor. Issues Ergon. Sci., vol. 4, no. 1-2, pp. 200-219, Jan. 2003.

[31] B. Hilburn, P. G. Jorna, E. A. Byrne, and R. Parasuraman, "The effect of adaptive air traffic control (ATC) decision aiding on con- troller mental workload," in Human-Automation Interaction: Research and Practice, M. Mouloua and J. Koonce, Eds. 1997, pp. 84-91.

[32] P. Aricò et al., "Adaptive Automation Triggered by EEG-Based Mental Workload Index: A Passive Brain-Computer Interface Application in Realistic Air Traffic Control Environment," Front. Hum. Neurosci., p. 539, 2016.

[33] M. W. Scerbo, F. G. Freeman, P. J. Mikulka, R. Parasuraman, F. Di Nocero, and L. J. Prinzel, "The Efficacy of Psychophysiological Measures for Implementing Adaptive Technology," NASA Langley Technical Report Server, 2001.

[34] W. R. Taggart, "Crew Resource Management: Achieving enhanced flight operations," Aviation Psychology in Practice, pp. 309-339, 1994.

[35] R. L. Helmreich, "Managing human error in aviation," Sci. Am., vol. 276, no. 5, pp. 62-67, May 1997.

[36] D. Harris, Ed., Engineering Psychology and Cognitive Ergonomics, vol. 9174. Cham: Springer International Publishing, 2015.
[37] L. L. Leape and J. A. Fromson, "Problem doctors: is there a system-level solution?," Ann. Intern. Med., vol. 144, no. 2, pp. 107-115, Jan. 2006.

[38] P. Aricò, G. Borghini, G. Di Flumeri, and F. Babiloni, "Metodo per stimare uno stato mentale, in particolare un carico di lavoro, e relativo apparato (A Method for the estimation of mental state, in particular of the mental workload and its device)," P1108IT00, 14-Sep-2015.

[39] G. Borghini et al., "Quantitative Assessment of the Training Improvement in a Motor-Cognitive Task by Using EEG, ECG and EOG Signals," Brain Topogr., Jan. 2015.

[40] G. Borghini et al., "Frontal EEG theta changes assess the training improvements of novices in flight simulation tasks," Conf. Proc. Annu. Int. Conf. IEEE Eng. Med. Biol. Soc. IEEE Eng. Med. Biol. Soc. Annu. Conf., vol. 2013, pp. 6619-6622, 2013.

[41] G. Borghini, L. Astolfi, G. Vecchiato, D. Mattia, and F. Babiloni, "Measuring neurophysiological signals in aircraft pilots and car drivers for the assessment of mental workload, fatigue and drowsiness," Neurosci. Biobehav. Rev., vol. 44, pp. 58-75, Jul. 2014.

[42] N. Ramnani and A. M. Owen, "Anterior prefrontal cortex: insights into function from anatomy and neuroimaging," Nat. Rev. Neurosci., vol. 5, no. 3, pp. 184-194, Mar. 2004.

[43] J. N. Wood and J. Grafman, "Human prefrontal cortex: processing and representational perspectives," Nat. Rev. Neurosci., vol. 4, no. 2, pp. 139-147, Feb. 2003.

[44] R. Cabeza and L. Nyberg, "Imaging cognition II: An empirical review of 275 PET and fMRI studies," $J$. Cogn. Neurosci., vol. 12, no. 1, pp. 1-47, Jan. 2000.

[45] K. Ryu and R. Myung, "Evaluation of mental workload with a combined measure based on physiological indices during a dual task of tracking and mental arithmetic," Int. J. Ind. Ergon., vol. 35, no. 11, pp. 991-1009, 2005.

[46] M. A. Hogervorst, A.-M. Brouwer, and J. B. F. van Erp, "Combining and comparing EEG, peripheral physiology and eye-related measures for the assessment of mental workload," Front. Neurosci., vol. 8, Oct. 2014.

[47] A. V. Medvedev, J. Kainerstorfer, S. V. Borisov, R. L. Barbour, and J. VanMeter, "Event-related fast optical signal in a rapid object recognition task: improving detection by the independent component analysis," Brain Res., vol. 1236, pp. 145-158, Oct. 2008.

[48] J. M. Murkin and M. Arango, "Near-infrared spectroscopy as an index of brain and tissue oxygenation," Br. J. Anaesth., vol. 103 Suppl 1, pp. i3-13, Dec. 2009.

[49] G. Derosière, K. Mandrick, G. Dray, T. E. Ward, and S. Perrey, "NIRS-measured prefrontal cortex activity in neuroergonomics: strengths and weaknesses," Front. Hum. Neurosci., vol. 7, Sep. 2013. 
[50] E. J. Calabrese, "Neuroscience and hormesis: overview and general findings," Crit. Rev. Toxicol., vol. 38, no. 4, pp. 249-252, 2008.

[51] D. Kirsh, "A Few Thoughts on Cognitive Overload," Intellectica, vol. 30, 2000.

[52] F. T. Eggemeier, G. F. Wilson, A. F. Kramer, and D. L. Damos, "Workload assessment in multi-task environments," in Multiple-task performance, D.L. Damos (Ed.)., London: Taylor\&Francis, 1991, pp. 207-216.

[53] D. Gopher and E. Donchin, "Workload: An examination of the concept," in Handbook of perception and human performance, Vol. 2: Cognitive processes and performance, John Wiley \& Sons., vol. 2, Oxford, England: John Wiley \& Sons, 1986, pp. 1-49.

[54] B. Cain, "A Review of the Mental Workload Literature," Jul. 2007.

[55] W. Boucsein and Backs Richard W., Engineering Psychophysiology: Issues and Applications. CRC Press, 2000.

[56] P. A. Desmond and P. A. Hancock, "Active And Passive Fatigue States," Stress Workload Fatigue, 2001.

[57] P. Aricò et al., "Towards a multimodal bioelectrical framework for the online mental workload evaluation," Conf. Proc. Annu. Int. Conf. IEEE Eng. Med. Biol. Soc. IEEE Eng. Med. Biol. Soc. Annu. Conf., vol. 2014, pp. 3001-3004, 2014.

[58] C. Berka et al., "EEG correlates of task engagement and mental workload in vigilance, learning, and memory tasks," Aviat. Space Environ. Med., vol. 78, no. 5 Suppl, pp. B231-244, May 2007.

[59] A. Gundel and G. F. Wilson, "Topographical changes in the ongoing EEG related to the difficulty of mental tasks," Brain Topogr., vol. 5, no. 1, pp. 17-25, 1992.

[60] S. Lei, S. Welke, and M. Roetting, "Driver's Mental Workload Assessment Using EEG Data in a Dual Task Paradigm," Proc. 21ST ESV Int. Tech. Conf. Enhanc. Saf. Veh. HELD JUNE 2009 Stuttg. Ger., 2009.

[61] S. Lei and M. Roetting, "Influence of Task Combination on EEG Spectrum Modulation for Driver Workload Estimation," Hum. Factors J. Hum. Factors Ergon. Soc., vol. 53, no. 2, pp. 168-179, Apr. 2011.

[62] M. E. Smith, A. Gevins, H. Brown, A. Karnik, and R. $\mathrm{Du}$, "Monitoring task loading with multivariate EEG measures during complex forms of human-computer interaction," Hum. Factors, vol. 43, no. 3, pp. 366380, 2001.

[63] J. R. Comstock, "MATB - Multi-Attribute Task Battery for human operator workload and strategic behavior research," Jan. 1994.

[64] G. F. Wilson, "Applied use of cardiac and respiration measures: practical considerations and precautions," Biol. Psychol., vol. 34, no. 2-3, pp. 163-178, Nov. 1992.
[65] A. Maglione et al., "Evaluation of the workload and drowsiness during car driving by using high resolution EEG activity and neurophysiologic indices," Conf. Proc. Annu. Int. Conf. IEEE Eng. Med. Biol. Soc. IEEE Eng. Med. Biol. Soc. Annu. Conf., vol. 2014, pp. 6238-6241, 2014.

[66] K. A. Brookhuis and D. de Waard, "The use of psychophysiology to assess driver status," Ergonomics, vol. 36, no. 9, pp. 1099-1110, Sep. 1993.

[67] A. T. Pope, E. H. Bogart, and D. S. Bartolome, "Biocybernetic system evaluates indices of operator engagement in automated task," Biol. Psychol., vol. 40, no. 1-2, pp. 187-195, May 1995.

[68] L. J. Prinzel, F. G. Freeman, M. W. Scerbo, P. J. Mikulka, and A. T. Pope, "A closed-loop system for examining psychophysiological measures for adaptive task allocation," Int. J. Aviat. Psychol., vol. 10, no. 4, pp. 393-410, Oct. 2000.

[69] A. Gevins et al., "Monitoring working memory load during computer-based tasks with EEG pattern recognition methods," Hum. Factors, vol. 40, no. 1, pp. 79-91, Mar. 1998.

[70] G. F. Wilson and F. Fisher, "Cognitive task classification based upon topographic EEG data," Biol. Psychol., vol. 40, no. 1-2, pp. 239-250, Maggio 1995.

[71] P. Aricò et al., "Reliability over time of EEG-based mental workload evaluation during Air Traffic Management (ATM) tasks," Conf. Proc. Annu. Int. Conf. IEEE Eng. Med. Biol. Soc. IEEE Eng. Med. Biol. Soc. Аnnu. Conf., vol. 2015, pp. 7242-7245, 2015.

[72] D. Heger, F. Putze, and T. Schultz, "Online Workload Recognition from EEG Data during Cognitive Tests and Human-Machine Interaction," in KI 2010: Advances in Artificial Intelligence, vol. 6359, R. Dillmann, J. Beyerer, U. D. Hanebeck, and T. Schultz, Eds. Berlin, Heidelberg: Springer Berlin Heidelberg, 2010, pp. 410-417.

[73] F. Putze, J.-P. Jarvis, and T. Schultz, "Multimodal Recognition of Cognitive Workload for Multitasking in the Car," in 2010 20th International Conference on Pattern Recognition (ICPR), 2010, pp. 3748-3751.

[74] S. I. Dimitriadis, Y. Sun, K. Kwok, N. A. Laskaris, N. Thakor, and A. Bezerianos, "Cognitive workload assessment based on the tensorial treatment of EEG estimates of cross-frequency phase interactions," Ann. Biomed. Eng., vol. 43, no. 4, pp. 977-989, Apr. 2015.

[75] G. Shou, L. Ding, and D. Dasari, "Probing neural activations from continuous EEG in a real-world task: time-frequency independent component analysis," $J$. Neurosci. Methods, vol. 209, no. 1, pp. 22-34, Jul. 2012.

[76] P. Aricò et al., "Air-Traffic-Controllers (ATCO) Neurophysiological analysis of training and workload ATCO," Ital. J. Aerosp. Med., vol. 12, pp. 18-35, Apr. 2015. 
[77] H. Ayaz, P. A. Shewokis, S. Bunce, K. Izzetoglu, B. Willems, and B. Onaral, "Optical brain monitoring for operator training and mental workload assessment," NeuroImage, vol. 59, no. 1, pp. 36-47, Jan. 2012.

[78] H. Ayaz et al., "Cognitive Workload Assessment of Air Traffic Controllers Using Optical Brain Imaging Sensors," in Advances in Understanding Human Performance, 0 vols., CRC Press, 2010, pp. 21-31.

[79] K. Izzetoglu, S. Bunce, B. Onaral, K. Pourrezaei, and B. Chance, "Functional Optical Brain Imaging Using Near-Infrared During Cognitive Tasks," Int. J. Hum.Comput. Interact., vol. 17, no. 2, pp. 211-227, Jun. 2004.

[80] C. Owen, "Beyond teamwork! Reconceptualising communication, coordination and collaboration in air traffic control," Hum Factors Aerosp. Saf, vol. 4, no. 4, pp. 289-306, 2005.

[81] B. Hilburn, R. Parasuraman, P. Jha, and K. McGarry, "Emerging human factors issues in future air traffic management," Cent. Hum. Perform. Res., Mar. 2006.

[82] S. Schultheis, "Integrating Advanced Technology into Air Traffic Controller Training," in 14th AIAA Aviation Technology, Integration, and Operations Conference, American Institute of Aeronautics and Astronautics, 2014.

[83] J. Rasmussen, Information Processing and HumanMachine Interaction: An Approach to Cognitive Engineering. New York, NY, USA: Elsevier Science Inc., 1986.

[84] J. Rasmussen, "Skills, rules, and knowledge; signals, signs, and symbols, and other distinctions in human performance models," IEEE Trans. Syst. Man Cybern., vol. SMC-13, no. 3, pp. 257-266, Maggio 1983.

[85] J. Rasmussen and K. Vicente, "Coping with Human Errors Through System Design: Implications for Ecological Interface Design," Int J Man-Mach Stud, vol. 31, no. 5, pp. 517-534, Nov. 1989.

[86] H. J. D. Reynolds, K. Lokhande, M. Kuffner, and S. Yenson, "Human-Systems Integration and Air Traffic Control," Linc. Lab. J., vol. 19, no. 1, pp. 26-28, 2012.

[87] J. M. Canino, J. B. Portas, J. M. Molina, and J. Garcìa, "A Multi-Agent Approach for Designing Next Generation of Air Traffic Systems," in Advances in Air Navigation Services, T. Magister, Ed. InTech, 2012.

[88] A. Cavcar and M. Cavcar, "New Directions for ATC Training A Discussion," Int. J. Aviat. Psychol., vol. 14, no. 2, 2004.

[89] C. D. Wickens, A. Mavor, and J. McGee, Flight to the Future: Human Factors in Air Traffic Control. Washington, D.C.: National Academies Press, 1997.

[90] E. Salas, C. A. Bowers, and E. Edens, Eds., Improving Teamwork in Organizations: Applications of Resource Management Training. Mahwah, N.J: CRC Press, 2001.
[91] K. I. Erickson et al., "Training-induced functional activation changes in dual-task processing: an FMRI study," Cereb. Cortex N. Y. N 1991, vol. 17, no. 1, pp. 192-204, Jan. 2007.

[92] D. Gopher, "Attention and Performance XIV (Silver Jubilee Volume)," D. E. Meyer and S. Kornblum, Eds. Cambridge, MA, USA: MIT Press, 1993, pp. 299-322.

[93] A. F. Kramer, J. L. Larish, T. A. Weber, and L. Bardell, "Training for executive control: Task coordination strategies and aging," in Attention and performance XVII: Cognitive regulation of performance: Interaction of theory and application, D. Gopher and A. Koriat, Eds. Cambridge, MA, US: The MIT Press, 1999, pp. 617-652.

[94] R. Parasuraman and R. A. McKinley, "Using Noninvasive Brain Stimulation to Accelerate Learning and Enhance Human Performance," Hum. Factors J. Hum. Factors Ergon. Soc., p. 0018720814538815 , Jun. 2014.

[95] K. Dobbs, "Breaking through the fog. Online Learning," Online Learn. Mag., pp. 36-42, Feb. 2001.

[96] K. W. Seibert, "Reflection-in-action: Tools for cultivating on-the-job learning conditions," Organ. Dyn., vol. 27, no. 3, pp. 54-65, 1999.

[97] W. J. Rothwell and H. C. Kazanas, Improving Onthe-Job Training: How to Establish and Operate a Comprehensive OJT Program. John Wiley \& Sons, 2004.

[98] G. J. Gery, Electronic Performance Support Systems: How and Why to Remake the Workplace Through the Strategic Application of Technology. Boston, MA, USA: Weingarten Publications, Inc., 1991.

[99] K. A. Ericsson, N. Charness, P. J. Feltovich, and R. R. Hoffman, The Cambridge Handbook of Expertise and Expert Performance. Cambridge University Press, 2006.

[100] E. Dahlin, L. Nyberg, L. Bäckman, and A. S. Neely, "Plasticity of executive functioning in young and older adults: Immediate training gains, transfer, and long-term maintenance," Psychol. Aging, vol. 23, no. 4, pp. 720-730, 2008.

[101] A. M. C. Kelly and H. Garavan, "Human Functional Neuroimaging of Brain Changes Associated with Practice," Cereb. Cortex, vol. 15, no. 8, pp. 10891102, Jan. 2005.

[102] H. Takeuchi, Y. Taki, and R. Kawashima, "Effects of Working Memory Training on Cognitive Functions and Neural Systems," Rev. Neurosci., vol. 21, no. 6, pp. 427-450, 2011.

[103] S. E. Petersen, H. van Mier, J. A. Fiez, and M. E. Raichle, "The effects of practice on the functional anatomy of task performance," Proc. Natl. Acad. Sci., vol. 95, no. 3, pp. 853-860, Mar. 1998.

[104] G. Vecchiato et al., "An electroencephalographic Peak Density Function to detect memorization during the observation of TV commercials," Conf. Proc. Annu. Int. Conf. IEEE Eng. Med. Biol. Soc. IEEE 
Eng. Med. Biol. Soc. Annu. Conf., vol. 2014, pp. 6969-6972, 2014.

[105] M. H. Beauchamp, A. Dagher, J. A. D. Aston, and J. Doyon, "Dynamic functional changes associated with cognitive skill learning of an adapted version of the Tower of London task," NeuroImage, vol. 20, no. 3, pp. 1649-1660, Nov. 2003.

[106] J. G. Milton, S. S. Small, and A. Solodkin, "On the Road to Automatic: Dynamic Aspects in the Development of expertise," J. Clin. Neurophysiol., no. 21, p. 134, 2004.

[107] R. A. Poldrack, "Imaging Brain Plasticity: Conceptual and Methodological Issues- A Theoretical Review," NeuroImage, vol. 12, no. 1, pp. 1-13, Luglio 2000.

[108] H. Garavan, D. Kelley, A. Rosen, S. M. Rao, and E. A. Stein, "Practice-related functional activation changes in a working memory task," Microsc. Res. Tech., no. 51, pp. 54-63, 2000.

[109] G. Borghini et al., "Skill, Rule and Knowledge-based Behaviour Detection by Means of ATCOs' Brain Activity," in 5th SESAR Innovation days, 2015.

[110] S. M. Jaeggi, M. Buschkuehl, J. Jonides, and W. J. Perrig, "Improving fluid intelligence with training on working memory," Proc. Natl. Acad. Sci., vol. 105, no. 19, pp. 6829-6833, 2008.

[111] C. A. Kothe and S. Makeig, "Estimation of task workload from EEG data: new and current tools and perspectives," Conf. Proc. Annu. Int. Conf. IEEE Eng. Med. Biol. Soc. IEEE Eng. Med. Biol. Soc. Conf., vol. 2011, pp. 6547-6551, 2011.

[112] E. L. Maclin et al., "Learning to multitask: Effects of video game practice on electrophysiological indices of attention and resource allocation," Psychophysiology, vol. 48, no. 9, pp. 1173-1183, Sep. 2011.

[113] K. E. Mathewson et al., "Different slopes for different folks: Alpha and delta EEG power predict subsequent video game learning rate and improvements in cognitive control tasks," Psychophysiology, vol. 49, no. 12, pp. 1558-1570, Dec. 2012.

[114] F. Taya et al., "Training-induced changes in information transfer efficiency of the brain network: A functional connectome approach," in 2015 7th International IEEE/EMBS Conference on Neural Engineering (NER), 2015, pp. 1028-1031.

[115] F. Taya, Y. Sun, F. Babiloni, N. Thakor, and A. Bezerianos, "Brain enhancement through cognitive training: a new insight from brain connectome," Front. Syst. Neurosci., vol. 9, p. 44, 2015.

[116] O. Sporns, "Contributions and challenges for network models in cognitive neuroscience," Nat. Neurosci., vol. 17, no. 5, pp. 652-660, May 2014.

[117] S. L. Bressler and V. Menon, "Large-scale brain networks in cognition: emerging methods and principles," Trends Cogn. Sci., vol. 14, no. 6, pp. 277-290, Jun. 2010.
[118] G. Borghini et al., "EEG-Based Cognitive Control Behaviour Assessment: an Eco-logical study with Professional Air Traffic Controllers," Sci. Rep. - Nat., In press.

[119] H. Ayaz et al., "Monitoring expertise development during simulated UAV piloting tasks using optical brain imaging," in 2012 IEEE Aerospace Conference, 2012, pp. 1-11.

[120] K. Gramann, T.-P. Jung, D. P. Ferris, C.-T. Lin, and S. Makeig, Towards a New Cognitive Neuroscience: Modeling Natural Brain Dynamics. Frontiers Ebooks, 2014.

[121] R. McKendrick, H. Ayaz, R. Olmstead, and R. Parasuraman, "Enhancing dual-task performance with verbal and spatial working memory training: Continuous monitoring of cerebral hemodynamics with NIRS," NeuroImage, vol. 85, Part 3, pp. 10141026, Jan 2014. 